\title{
Cooking Matters Mobile Application: a meal planning and preparation tool for low-income parents
}

\author{
Teresa M Garvin' ', Alethea Chiappone' ', Lisa Boyd' ', Katie Stern' ', Jill Panichelli², \\ Leigh Ann Edwards Hall ${ }^{2}$ and Amy L Yaroch ${ }^{1, *}$ \\ 'Gretchen Swanson Center for Nutrition, 8401 West Dodge Road, Suite 100, Omaha, NE 681 14, USA: ${ }^{2}$ Share Our \\ Strength, Washington, DC, USA
}

Submitted 30 July 2018: Final revision received 29 January 2019: Accepted 28 February 2019: First published online 14 May 2019

\begin{abstract}
Objective: To describe low-income parents' and caregivers' perceptions of the Cooking Matters Mobile Application (CMApp) meal planning and preparation features. Design: Explanatory mixed-methods design where data were gathered via online surveys based on the Theory of Planned Behaviour and the Theory of Reasoned Action, followed by telephone interviews.

Setting: CM App, a mobile phone-based resource geared towards low-income parents and caregivers of young children (pregnancy/infant to age 5 years) for meal planning and preparation, with features based on skills taught in the Cooking Matters course: recipes, shopping list and meal planning.

Participants: Low-income parents and caregivers (survey participants, $n 461$; interview participants, $n 20$ ) who had downloaded the CMApp to their smartphone and agreed to participate in the current evaluation.

Results: Attitudes and self-efficacy related to CM App's subject matter and functions (meal planning; recipe use; creating and using a shopping list) were measured via surveys and interviews. Mean (SD) responses were positive towards 'meal planning' and 'shopping and cooking' (4.17 (0.63) and $3.49(0.86)$ on a 5-point Likert scale, respectively). Interviewees described meal planning and preparation behaviours as intrinsic, based on habit, and influenced by family preference and food costs. Early adopters of the CM App may already be engaged in and/or are motivated to engage in the targeted health behaviours.

Conclusions: Users may benefit most from incorporating into their routines new ways to prepare easy, cost-efficient, healthy meals at home that their families will enjoy.
\end{abstract}

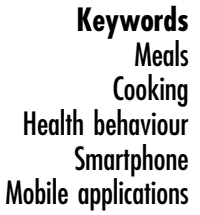

Poor dietary behaviours contribute to an increased risk for obesity, which is a significant public health concern in the USA among adults and children living in low-income households. Research has demonstrated a relationship between parent and child dietary behaviours ${ }^{(1,2)}$, which are potentially modifiable via home food behaviours and environment ${ }^{(3-5)}$. Specifically, frequent and skilful food preparation has been shown to be associated with healthier dietary intake, such as increased fruit and vegetable intake among young adults ${ }^{(6)}$, adolescents ${ }^{(7)}$ and low-income women ${ }^{(8)}$. Additionally, time spent preparing food is inversely related to BMI among racially and ethnically diverse samples of women ${ }^{(9,10)}$. Energy consumed from food prepared outside the home has increased in recent decades (18\% in 1977/1978 to $30 \%$ in 2009/2010) $)^{(11)}$, while consumption of food from the home supply, as well as time

spent preparing food, has decreased ${ }^{(12)}$. Healthier food preparation in the home may support existing healthful dietary patterns among adults and their children and may eventually shift trends towards more frequent consumption of healthier foods prepared at home.

Share Our Strength's Cooking Matters campaign empowers caregivers with essential food skills to improve the health and well-being of their families and young children ${ }^{(13,14)}$. Cooking Matters, much like other cooking or food preparation-based interventions, is modelled based on the Social Cognitive Theory ${ }^{(15)}$, primarily focusing on observed learning and mastery experiences via classes or demonstrations in community or clinical settings ${ }^{(13,16)}$. Constructs addressed via Cooking Matters and other cooking and food preparation-based interventions often include knowledge and skills, attitudes and self-efficacy related to food preparation ${ }^{(13,16)}$, 
which may be supported by behaviours such as planning meals before going grocery shopping, creating and following a shopping list, and utilizing recipes ${ }^{(17,18)}$. Participants of the Cooking Matters for Adults course have reported improved dietary behaviours (e.g. more fruit intake), food-resource management and self-efficacy with regard to food preparation and cooking ${ }^{(13,14)}$. While effective, the in-person courses, which are designed to be two hours per week for six weeks, may limit reach to only families who are inclined or able to attend, prompting the exploration into new methods for reaching low-income parents and caregivers of young children.

In June 2017, Share Our Strength, in partnership with Savvy Apps, launched the Cooking Matters Mobile Application (CM App), a mobile phone-based resource geared towards low-income parents and caregivers of young children (pregnancy/infant to age 5 years) for meal planning and preparation, with features based on skills taught in the Cooking Matters course: recipes, shopping list and meal planning. Since over $77 \%$ of Americans own a smartphone and $64 \%$ of smartphone users live in households earning less than \$US 30000 per year, there is potential for broad reach of mobile health (mHealth) technology, which includes using mobile and wireless devices to improve health outcomes among lower-income populations ${ }^{(19)}$. Emerging research has suggested that mobile apps may be an effective approach to supporting healthier food purchasing behaviours ${ }^{(20)}$, healthier food preparation methods ${ }^{(21)}$, and healthier recipe management and meal planning behaviours ${ }^{(22)}$, but that there is a need to engage mobile app users and nutrition professionals in the design.

The goal of the CM App was to better reach parents of young children with tools that enable planning, shopping for and cooking healthy meals on a budget ${ }^{(13,14)}$. While the use of mHealth may facilitate modest improvements that encourage behaviour change ${ }^{(23)}$, it was unknown how a meal planning and preparation-based mobile application would be utilized and perceived by low-income families with young children. The purpose of the present study was to understand confidence and attitudes regarding meal planning and preparation, as well as meal planning and preparation behaviours, of low-income parents and caregivers who downloaded the CM App to their mobile phone. Further, the study aimed to explore their perceptions of the CM App's meal planning and preparation features. Findings from the study were used to make recommendations for the next iteration of the CM App and apps of this nature.

\section{Methods}

\section{Study design}

An explanatory mixed-methods approach was utilized in which quantitative data were first gathered via online surveys administered to an audience of CM App users who were also parents and guardians to assess potential psychosocial correlates (e.g. instrumental attitude, experiential attitude, perceived control and self-efficacy) of recipe use, shopping list development and meal planning ${ }^{(24)}$. Qualitative data were then collected via semi-structured interviews administered to a sub-sample of survey respondents who were also members of the intended audience (i.e. low-income parents and caregivers of young children) to supplement quantitative findings ${ }^{(24)}$. Survey participants were invited to complete a follow-up survey approximately one month after completing the first survey, but despite numerous recruitment attempts, the sample size was low and therefore the post-test findings are not included in the current paper. Study activities were approved by the University of Nebraska Medical Center Institutional Review Board.

\section{Surveys}

\section{Participants and recruitment}

In June 2017, the CM App was available for download to the public via the Google Play Store on Android devices. In order to ensure that the intended audience was aware of the CM App, direct advertisement took place at state and local levels of federal food assistance programme offices, such as the Special Supplemental Nutrition Program for Women, Infants, and Children (WIC). The app was also promoted to attendees of a national Head Start conference that took place in September 2017. From June to October 2017, CM App users were recruited to participate in the web-based survey via a promotional banner in the app that read, 'Parents! Tap here to earn $\$ 10$ for completing a quick survey'. The promotional banner was shown only after the initial download, thus prior to use of the app. If they tapped the banner prior to using the app, users were asked two screener questions: the number of child(ren) between the ages of 0 and 5 years who lived in their household and the number of children between the ages of 6 and 18 years who lived in their household. If the participant answered ' 0 ' to both questions, s/he was automatically disqualified from the survey. Five hundred and fifty-four users completed the screener and ninety-three were excluded due to responding ' 0 ' to both screener questions or taking the survey more than once, resulting in a final analytical sample of 461 .

\section{Survey instrument}

Survey items were based on integrated constructs from the Theory of Planned Behaviour and the Theory of Reasoned Action $^{(25)}$ to assess potential correlates (e.g. instrumental attitude, experiential attitude, perceived control and selfefficacy) of CM App's subject matter and features: cooking, recipe use, shopping list development and meal planning. These theories posit that constructs and other factors influence intention to perform a behaviour, as well as the behaviour itself, and therefore focus on the potential for incremental behaviour change, which may be more 
appropriate for evaluating a mobile app than actual change to dietary intake and patterns of intake ${ }^{(23)}$.

An initial list of validated and new items that addressed several theoretical constructs from the Theory of Planned Behaviour and the Theory of Reasoned Action, as well as perceived barriers, was compiled by the research team, who then worked with Share Our Strength and Savvy Apps to narrow down the items to those of highest interest to the study (i.e. instrumental attitude, experiential attitude and self-efficacy). Instrumental attitude is the belief about outcomes of a behavioural performance (e.g. 'Using a shopping list would help me stay on budget to buy enough groceries'), experiential attitude is the emotional response to the idea of performing a behaviour (e.g. 'Cooking meals at home takes too much time') and self-efficacy is the confidence in the ability to perform the behaviour in the face of barriers (e.g. 'I am confident that I can cook a well-balanced meal at home most evenings during the week') $)^{(25)}$. The survey was then tested in the field at a local Cooking Matters for Adults class and minor adjustments for clarity and verbiage were made.

The final version of the survey was administered to users via Qualtrics software (Qualtrics, Provo, UT, USA) and was intended to take about $5 \mathrm{~min}$ to complete. Including the two screener questions, the final survey was twenty items in total. Survey participants received a \$US 10 e-gift card emailed to them by Share Our Strength. Twelve items were newly developed or modified from existing survey items ${ }^{(14,26-28)}$ and asked about: types of meals eaten for dinner during a typical week (two items); grocery shopping (two items); planning meals (four items); using a shopping list (one item); and cooking meals (three items). For items that asked about types of meals eaten for dinner during a typical week (e.g. 'Thinking about a typical week (including the weekend), about how many times does your family eat a home-prepared meal for dinner?'), response options ranged from 0 to 7 times/week. For items that asked about grocery shopping (e.g. 'How often do you plan meals before you go grocery shopping?'), Likert-scale response options ranged from 'never' to 'always'. For all other items (e.g. 'Planning meals before I go grocery shopping takes too much time'), responses included Likert-scale options ranging from 'strongly disagree' to 'strongly agree'. Four sociodemographic questions including participation in federal and (WIC; Supplemental Nutrition Assistance Program (SNAP)) non-federal food assistance programmes (e.g. food pantry), race/ethnicity (non-Hispanic White; non-Hispanic Black or African American; Hispanic/ Latino(a); Multiracial/Other races/ethnicities), education ( $\leq$ high school or General Education Development (GED) diploma; >high school or GED diploma) and annual income ( $<$ \$US $25000 ; \geq \$$ US 25000 ).

\section{Survey data analyses}

Statistical analysis was conducted using the statistical software package SAS for Windows version 9.4. Frequencies and percentages were reported for survey characteristics. Medians and ranges were reported for frequencies of home-prepared meals and frozen or boxed meals because data were not normally distributed. Exploratory factor analysis was conducted on ten items (the two items addressing types of meals eaten for dinner during a typical week were excluded because they asked about frequency and not about potential psychosocial correlates) using SAS PROC FACTOR, with eigenvalues $>1$ considered for scales. Two scales emerged from the ten survey items that asked about correlates of dietary behaviours related to CM App's subject matter and functions. The first scale was described as the 'perceptions of meal planning' scale (five items; see Table 2 for survey items) and the second scale was described as the 'perceptions of shopping and cooking' scale (four items; see Table 3 for survey items). One item was not statistically associated with either scale and therefore was a standalone item: 'Cooking meals at home doesn't take too much time'. At the scale level, means and SD of observed summed scores were calculated. Internal consistency was measured using Cronbach's $\alpha$. Means and SD were computed at the item level.

\section{Interviews}

\section{Participants and recruitment}

While the CM App was available to the general public, it was designed for an audience of low-income parents and caregivers of young children (pregnancy/infant to age 5 years). In order to better understand this intended audience, survey participants were eligible to be interviewed if they indicated they were a parent of a child between the ages of 0 and 5 years and a participant in at least one federal food assistance programme. Those eligible were recruited to participate via prompting at the end of the survey or direct emails. Trained interviewers conducted interviews over the telephone until themes were saturated. Of the forty-six individuals invited to participate, three declined to participate, sixteen did not respond to interview requests, seven did not respond to multiple interview attempts, and twenty completed an interview (eighteen females, two males). Interviewees ranged in their reported use of the CM App, from those who were no longer using the app at the time of the interview to those who said they used it multiple times per week. Interviewees were emailed \$US 20 e-gift cards for participating.

\section{Interview guide}

A semi-structured interview guide was developed with input from Share Our Strength and Savvy Apps, to supplement findings from the survey, in particular: (i) mealtime routines and habits; (ii) meal planning behaviours and attitudes; (iii) grocery shopping behaviours and attitudes; and (iv) perceptions of and experiences with the CM App features and functions. Interview guide questions were 
tailored to the interviewee based on whether analytical data showed s/he opened the CM App after the initial download or not. Initially, interviews were intended to last $60 \mathrm{~min}$, but were later shortened to $30 \mathrm{~min}$ due to recruitment difficulties.

\section{Interview data analyses}

Interviews were audio-recorded, transcribed verbatim and analysed using the qualitative data analysis software NVivo version 11 (QRS International Pty Ltd, 2017). Two members of the research team independently reviewed transcripts and developed an initial list of codes using a Grounded Theory approach, where theory is generated as data are collected $^{(29)}$. The list of codes was then reviewed and discrepancies were discussed further until consensus was reached, resulting in a final list (available upon request). To ensure inter-coder reliability, a constant comparison methodology was employed whereby two coders used the initial code list to independently review ten transcripts each ${ }^{(29)}$. Codes were grouped into conceptual themes through frequency of coding within similar context across interviews.

\section{Results}

\section{Surveys}

Four hundred and sixty-one participants met eligibility criteria and were included in the analytical sample. Approximately $70 \%$ of the participants had at least one child aged $0-5$ years and $70 \%$ had at least one child aged 6-18 years (Table 1 ). A majority (59\%) reported an annual income of less than \$US 25000 . Almost half (43\%) of the participants reported participating in WIC and $62 \%$ participated in SNAP. Forty per cent identified as nonHispanic White, $33 \%$ as Hispanic/Latino(a) and $18 \%$ as non-Hispanic Black or African American.

Participants indicated their families ate home-prepared meals a median of 5 times/week and ate frozen or boxed meals a median of 2 times/week (out of a maximum of 7 times/week). The 'perceptions of meal planning' scale resulted in a mean score of 3.49 (SD 0.86) out of a maximum of 5 with strong internal consistency (Cronbach's $\alpha=0 \cdot 79$; Table 2). The 'perceptions of shopping and cooking' scale resulted in a mean score of 4.17 (SD 0.63 ) out of a maximum of 5 with moderate internal consistency (Cronbach's $\alpha=0 \cdot 72$; Table 3). The item that did not load in either scale, 'Cooking meals at home doesn't take too much time', had a mean of 3.74 (SD 1.05).

\section{Interviews}

Six salient themes emerged from the twenty interviews and included: (i) barriers to meal planning; (ii) occasional creation and use of a simple shopping list; (iii) multiple influences on grocery shopping habits; (iv) recipes used as guidelines or inspiration; (v) influences on meal preparation behaviours; and (vi) recipe feature of CM App.
Table 1 Characteristics of survey participants: low-income parents and caregivers who had downloaded the Cooking Matters Mobile Application ( $n$ 461), USA, June-October 2017

\begin{tabular}{|c|c|c|}
\hline Characteristic & $n$ & $\%$ \\
\hline $\begin{array}{l}\text { Parent of child(ren) between the ages } \\
\text { of } 0 \text { and } 5 \text { years }\end{array}$ & 320 & $69 \cdot 4$ \\
\hline $\begin{array}{l}\text { Parent of child(ren) between the ages } \\
\text { of } 6 \text { and } 18 \text { years }\end{array}$ & 321 & $69 \cdot 6$ \\
\hline \multicolumn{3}{|l|}{ Race/ethnicity } \\
\hline Non-Hispanic White & 166 & 39.5 \\
\hline Non-Hispanic Black or African American & 74 & $17 \cdot 6$ \\
\hline Hispanic/Latino(a) & 137 & 32.6 \\
\hline Multiracial/Other races/ethnicities & 43 & $10 \cdot 2$ \\
\hline \multicolumn{3}{|l|}{ Education } \\
\hline$\leq$ High school or GED diploma & 181 & $43 \cdot 1$ \\
\hline > High school or GED diploma & 239 & $56 \cdot 9$ \\
\hline \multicolumn{3}{|l|}{ Annual income } \\
\hline$<\$$ US 25000 & 270 & $58 \cdot 6$ \\
\hline \multicolumn{3}{|l|}{$\begin{array}{l}\text { Participation in federal food assistance } \\
\text { programmes }\end{array}$} \\
\hline WIC & 196 & 42.5 \\
\hline SNAP & 287 & $62 \cdot 3$ \\
\hline
\end{tabular}

WIC, Special Supplemental Nutrition Program for Women, Infants, and Children; SNAP, Supplemental Nutrition Assistance Program; GED, General Education Development.

Totals may not add up to 461 because of missing data.

Table 2 Mean score and SD for items within the 'perceptions of meal planning' scale among low-income parents and caregivers who had downloaded the Cooking Matters Mobile Application ( $n$ 461), USA, June-October 2017

\begin{tabular}{lll}
\hline Item & Mean & SD \\
\hline $\begin{array}{l}\text { I am confident that I can plan meals before I go } \\
\text { grocery shopping }\end{array}$ & 3.84 & 1.04 \\
$\begin{array}{l}\text { It is important to me to plan meals before I go } \\
\text { grocery shopping }\end{array}$ & 3.61 & 1.07 \\
$\begin{array}{l}\text { How often do you use a shopping list when you go } \\
\text { grocery shopping? }\end{array}$ & 3.41 & 1.31 \\
$\begin{array}{l}\text { Planning meals before I go grocery shopping } \\
\text { doesn't take too much time* }\end{array}$ & 3.39 & 1.09 \\
$\begin{array}{l}\text { How often do you plan meals before you go grocery } \\
\text { shopping? }\end{array}$ & 3.22 & 1.22 \\
\hline
\end{tabular}

Mean (SD), range of overall scale: $3.49(0.86), 1.20-5 \cdot 00$; Cronbach's $\alpha=0.79$. *Item reverse-coded.

Table 3 Mean score and SD for the items within the 'perceptions of shopping and cooking' scale among low-income parents and caregivers who had downloaded the Cooking Matters Mobile Application ( $n$ 461), USA, June-October 2017

\begin{tabular}{llc}
\hline Item & Mean & SD \\
\hline $\begin{array}{l}\text { It is important to me to cook a well-balanced meal at } \\
\text { home most evenings during the week }\end{array}$ & 4.29 & 0.72 \\
$\begin{array}{l}\text { Using a shopping list would help me stay on budget } \\
\text { vto buy enough groceries }\end{array}$ & 4.18 & 0.87 \\
$\begin{array}{l}\text { Planning meals before I go grocery shopping would } \\
\text { help me/my family cook meals at home }\end{array}$ & 4.13 & 0.92 \\
$\begin{array}{l}\text { I am confident that I can cook a well-balanced meal } \\
\text { at home most evenings during the week }\end{array}$ & 4.08 & 0.83 \\
\hline
\end{tabular}

Mean (SD), range of overall scale: 4.17 (0.63), 1.00-5.00; Cronbach's $\alpha=0.72$. 


\section{Barriers to meal planning}

Most interviewees stated that they did not plan specific, daily meals prior to grocery shopping due to lack of time, inability to stick to the meal plan, plans changing and simply because they chose to not plan meals. One interviewee stated:

'I think for me that it's a waste of time to just spend two hours planning meals if when I'm going to get to the store, I will see something different and I will want something different than what I already planned.'

For the few who planned meals ahead of grocery shopping, it generally occurred the day of the meal or as a weekly routine.

\section{Occasional creation and use of a simple shopping list} Most interviewees reported that they 'sometimes' created a shopping list. When creating shopping lists, simplicity was key, as a majority said that they preferred using pen and paper. Others described using electronic methods (e.g. phone, text message, other mobile applications) or a mix of methods, mostly whichever mode was most convenient at the moment. In determining what to put on the shopping list, interviewees explained that decisions were made mainly based on what ingredients they ran out of, sales and coupons, and a usual set of products they typically purchased. Reasons for not creating shopping lists included that they did not have enough time, did not stick to the list, only needed a few items, kept the list in their head, purchased 'the usual' or simply did not use grocery shopping lists.

\section{Multiple influences on grocery shopping habits}

Foods purchased at the grocery store were influenced by an amalgamation of factors: browsing the store's selection, impulse purchases, child(ren)'s wants and especially store sales. Interviewees also described using a shopping list, as well as purchasing a basic set of items they needed and typically used. One stated:

'We just go and try to remember what we eat and what we need, which is almost every time the same.'

Interviewees described making larger grocery shopping trips and augmenting with occasional smaller trips to stores for supplemental items (e.g. perishable products). Lastly, prices, products available, and distance from home, work or public transportation were important factors in where they shopped.

\section{Recipes used as guidelines or inspiration}

While many interviewees stated they did not regularly use recipes, most said that recipe use was dependent on the type of meal they cooked. Some used recipes to incorporate new meals into their routines or as a guideline or inspiration for a meal. One said:
'I probably use them [recipes] about $75 \%$ of the time, at least as reference. I don't always necessarily stay exactly with it.'

Interviewees preferred recipes with short meal preparation times, as well as ones that were simple and required few ingredients. Recipes were usually obtained from the Internet and mobile applications due to the availability and abundance; as one interviewee described, they appreciated being able to find recipes that used ingredients already on hand.

\section{Influences on meal preparation behaviours}

Meals and snacks prepared were often a result of what ingredients or items interviewees had on hand at home. Interviewees also explained that they had a set of 'go-to' meals they were comfortable with, as one person stated:

'I made a list of everything I know how to cook, and normally I just pick from there.'

Interviewees also said the meals they chose to cook were influenced by their children's food preferences. Interviewees mainly noted that they felt confident in their ability to cook well-balanced meals at home; however, they described that a tight budget and their children as picky eaters affected their ability to cook well-balanced meals. Many interviewees described wanting to make time for dinners and eating as a family, but work schedules, children's activities and getting children to bed at a reasonable time were commonly cited as barriers to doing so. In instances when interviewees were short on time or they did not end up preparing the meal that they planned to prepare, they mostly described preparing simpler meals, eating leftovers or purchasing takeaway meals.

\section{Recipe feature of CM App}

For those who said they had been using the app since the initial download (compared with those who described themselves as having downloaded it, but not using it), the recipe feature was most often utilized. A common theme among interviewees was using the CM App's recipe catalogue for inspiration, specifically for new and healthier ways to make meals they were already familiar with preparing. Interviewees mentioned that they appreciated that the recipes were aesthetically appealing and not overly timeconsuming, as lack of time was identified as a prominent barrier to meal preparation. However, they identified that they wanted to see more recipes (e.g. quick meals, crockpot, freezer-friendly) that could alleviate this barrier.

The meal planning and grocery list features were used to a lesser extent or not at all, either because interviewees did not know these tools were included in the CM App, or they had established habits in these areas or they did not have a desire to establish a new habit. Some interviewees identified mobile phone data usage as a barrier to using these features in locations (e.g. grocery store) where Wi-Fi was not available and recommended an offline feature. Lastly, 
interviewees described that weekly meal planning recommendations and making the shopping list sharable across members of a household may increase their usage of these features.

\section{Discussion}

The present study aimed to understand behaviours, confidence and attitudes regarding meal planning and preparation of low-income parents and caregivers who downloaded the CM App to their mobile phone. While many mobile applications exist with goals of changing nutrition and dietary behaviours, most have been developed with a lack of evidence-based features or lack of consumer appeal ${ }^{(23)}$. The CM App was a collaborative process between Share Our Strength and Savvy Apps, who were also key partners in the evaluation, which contributed to a study where findings were applicable in a 'real-world' setting. Overall, findings suggested that survey participants may already be engaged in and/or are motivated to meal plan. Interestingly, interviewees generally did not consider themselves to be meal planners, but rather being adapt at having to fit meals into hectic day-to-day schedules. In survey participants and interviewees, meal planning, shopping list development and food purchasing may happen concurrently and intermittently, and behaviours appeared to be intrinsic, highly based on habit, and influenced by family preference and food costs.

The present study also aimed to explore interviewees' perceptions of the CM App's meal planning and preparation features in order to make recommendations for the next iteration of the CM App and apps of this nature. Early adopters of the CM App, much like those who use other apps of this nature, were already engaged in and/ or motivated to engage in targeted health behaviours (i.e. cooking, recipe use, shopping list development, meal planning), which may be indicative of potential for incremental change to promote healthier dietary patterns ${ }^{(23)}$, but not behaviour change. Thus, the CM App and apps of this nature should consider that when the audience is derived from the general population, users likely have high levels of confidence in and positive attitudes towards their current meal planning, grocery shopping and meal preparation habits. This suggests that the development of subject matter and functions should be tailorable to a variety of current behaviours and habits.

\section{Meal preparation and cooking}

As a whole, the proportion of time spent cooking has decreased from 1965 to 2007 across all income groups, but it has decreased the most among low-income people, which has not been compensated by increased eating out, suggesting a greater reliance upon foods requiring little preparation $^{(12)}$. Other studies have shown that low-income households exhibited a higher likelihood of either always or never cooking dinner at home (as opposed to sometimes cooking dinner at home), suggesting that low-income household are engaging in a response to other circumstances $^{(30,31)}$. As previously stated, more frequent and skilful food preparation, as well as cooking enjoyment, may be associated with healthier dietary intake ${ }^{(6-8,32)}$. When looking at specific items that make up the "perceptions of shopping and cooking' scale, respondents reported highly valuing cooking well-balanced meals at home, but being less confident in their ability to cook meals at home. Interestingly, interviewees said they often cooked simple meals that they knew their families like or relied on takeaway meals. Neither of these necessarily falls outside the realm of cooking well-balanced meals at home, as they can serve as components of cooking meals at home (e.g. paring a takeaway meal with a vegetable side-dish cooked at home). These responses aligned with previous literature, which has demonstrated variability among interpretations of what home cooking means to individuals, as well as differences among perceived time and effort necessary to cook a meal at home ${ }^{(33,34)}$. Considering ways to tailor the CM App content and features so that it recognizes and incorporates simple and quick meals that CM App users are already preparing (e.g. frozen pizza or chicken nuggets) into healthier meals may help dispel any preconceived notions that cooking meals at home requires excessive time and effort. It may also assist users in preparing healthier meals for their families. Further, tailoring the app may encourage users to incorporate more frequent and skilful food preparation into their regular routines, potentially contributing to healthier diets ${ }^{(8)}$.

\section{Recipe and meal planning features}

The recipe feature, which was described as inspirational for incorporating more fruits and vegetables into meals, was considered the favourite feature among users. The moderate perceptions of meal planning, indicated by the mean score of 3.49 on the 'perceptions of meal planning' scale, may give indication that the recipe feature fit well into users' current habits, perhaps supporting healthier food preparation, rather than prompting making lifestyle changes. Planning meals ahead of time has been shown to be associated with increased intake of fruits and vegetables among women $^{(17)}$ and also has the potential to contribute to food security in a household ${ }^{(35)}$; however, the literature on this topic is limited with regard to what constitutes meal planning. In the present study, the recipe feature was well liked, but the meal planning feature of the CM App received relatively less favour or interest and interviewees did not consider themselves to be meal planners. Despite this selfassessment, they described engaging in meal planningrelated skills, such as often cooking meals that they had confidence in making and knew that their families would eat, as well as having an adaptable framework in mind 
where they would swap specific meals or foods (e.g. type of meat or vegetable) while grocery shopping based on what is on sale. While CM App users may benefit from practical sessions to increase cooking self-efficacy on the topics of meal planning and other methods such as batch cooking and freezing to facilitate cooking from scratch ${ }^{(33)}$, they would need to be delivered via mobile application in a way that allows individuals to incorporate practices into their current habits and lifestyles, such as through short demonstration videos. More exploration is needed on meal planning practices across households in order to better define meal planning and learn ways that mobile applications may enhance a variety of current practices.

\section{Creating a shopping list and grocery shopping}

Creating a shopping list may support healthy dietary behaviours $^{(6,17)}$, especially among high-risk adults ${ }^{(36)}$. Unexpectedly, despite the very positive perceptions of shopping and cooking (indicated by the scale mean score of 4.17), interviewees did not respond favourably to using a shopping list or the shopping list feature of the CM App. Interviewees indicated that they made food purchasing decisions based on what is cheapest, on sale and/or coupons, which may be especially prominent given that participants were sampled from a low-income population. Among those who reported creating shopping lists, they preferred using pen and paper and seemed unwilling to change their current habits. Studying grocery list habits may help determine if there are opportunities to support grocery list development and use in general, but also via the CM App or mobile applications of this nature.

\section{Study limitations}

These findings should be interpreted with a level of caution, as there are limitations to the present study. First, survey and interview respondents were comprised of a convenience sample of CM App users, suggesting findings may not be generalizable to other populations. Second, all data were self-reported and likely influenced by social desirability bias. For example, participants know meal planning, creating a shopping list and recipe usage are considered 'good' behaviours, so they may have rated themselves higher than they actually were at these tasks. Third, while the survey resulted in good reliability as assessed through internal consistency of scales, the present study did not allow for validity testing, so the extent to which the survey items measured what they intended to measure is unknown. Fourth, users who were recruited may have been highly motivated to use the CM App; wanting to collect an incentive; early adopters of this technology (meaning they may not represent the majority of the population) ${ }^{(37)}$; and/or willing and available to participate in the surveys and interviews. Also, this method did not allow for understanding the reach of the survey to the potential audience compared with the responding sample. Despite these limitations, there were also several strengths of the present study. Chiefly, not many mobile applications of this type have been evaluated, so lessons learned will be highly valuable to future iterations of the CM App, as well as potentially contributing to the development and study of other evidence-based dietary behaviour apps. The relatively large sample size for the survey allowed for psychometric testing of survey scales. Also, survey participants comprised a relatively large representation of the target population (62\% of survey respondents participated in SNAP and all interviewees participated in at least one federal food assistance programme). Last, the mixed-methods approach to collect both quantitative and qualitative data allowed for elaboration on and interpretation of survey findings.

\section{Conclusions}

Early adopters of the CM App, much like those who use other apps of this nature, appear to be motivated to engage in the targeted health behaviours ${ }^{(23)}$ and may benefit from support for small changes, such as incorporating into their routines new ways to prepare easy, cost-efficient, healthy meals at home that that their families will enjoy. While aspects of the CM App were received well by the intended audience, the present study highlights considerations for improving reach, and potentially adoption, of the CM App. Primarily, it is recommended that apps of this nature be tailored to audiences of varying levels of confidence in and attitudes towards meal planning, grocery shopping-list use and recipe use, specifically aiming to incrementally enhance current habits and behaviours towards healthier habits and behaviours in order to have a broader reach.

\section{Acknowledgements}

Acknowledgements: The authors thank Share Our Strength for funding this evaluation and Savvy Apps for developing the CM App and participating in this evaluation. Financial support: This evaluation was funded by Share Our Strength. Conflict of interest: There are no conflicts of interest to report. Authorship: A.C. and K.S. collected the data. T.M.G. wrote the first draft with contributions from A.C., L.B. and K.S. All authors reviewed and commented on subsequent drafts of the manuscript. Ethics of human subject participation: This study was conducted according to the guidelines laid down in the Declaration of Helsinki and all procedures involving human subjects were approved by the University of Nebraska Institutional Review Board. Informed consent was obtained from all subjects.

\section{References}

1. Smith TM, Calloway EE, Pinard CA et al. (2017) Using secondary 24-hour dietary recall data to estimate daily dietary 
factor intake from the FLASHE study dietary screener. $A m$ J Prev Med 52, 856-862.

2. Robson SM, Couch SC, Peugh JL et al. (2016) Parent diet quality and energy intake are related to child diet quality and energy intake. J Acad Nutr Diet 116, 984-990.

3. Loth KA, Horning M, Friend S et al. (2017) An exploration of how family dinners are served and how service style is associated with dietary and weight outcomes in children. $J$ Nutr Educ Behav 49, 513-518.e1

4. Couch SC, Glanz K, Zhou C et al. (2014) Home food environment in relation to children's diet quality and weight status. J Acad Nutr Diet 114, 1569-1579.

5. Wyse R, Campbell E, Nathan N et al. (2011) Associations between characteristics of the home food environment and fruit and vegetable intake in preschool children: a crosssectional study. BMC Public Health 11, 938.

6. Larson NI, Perry CL, Story M et al. (2006) Food preparation by young adults is associated with better diet quality. J Am Diet Assoc 106, 2001-2007.

7. Larson NI, Story M, Eisenberg ME et al. (2006) Food preparation and purchasing roles among adolescents: associations with sociodemographic characteristics and diet quality. J Am Diet Assoc 106, 211-218.

8. McLaughlin C, Tarasuk V \& Kreiger N (2003) An examination of at-home food preparation activity among low-income, food-insecure women. J Am Diet Assoc 103, 1506-1512.

9. Zick CD, Stevens RB \& Bryant WK (2011) Time use choices and healthy body weight: a multivariate analysis of data from the American Time Use Survey. Int J Behav Nutr Phys Act 8, 84 .

10. Kolodinsky JM \& Goldstein AB (2011) Time use and food pattern influences on obesity. Obesity (Silver Spring) 19, $2327-2335$.

11. Todd JE \& Mentzer Morrison R (2014) Less Eating Out, Improved Diets, and More Family Meals in the Wake of the Great Recession. Washington, DC: US Department of Agriculture, Economic Research Service.

12. Smith LP, Ng SW \& Popkin BM (2013) Trends in US home food preparation and consumption: analysis of national nutrition surveys and time use studies from 1965-1966 to 2007-2008. Nutr J 12, 45.

13. Pooler JA, Morgan RE, Wong K et al. (2017) Cooking Matters for Adults improves food resource management skills and self-confidence among low-income participants. I Nutr Educ Behav 49, 545-553.e1.

14. Pinard CA, Uvena LM, Quam JB et al. (2015) Development and testing of a revised Cooking Matters for Adults survey. Am J Health Behav 39, 866-873.

15. Bandura A (2004) Health promotion by social cognitive means. Health Educ Behav 31, 143-164.

16. Reicks M, Trofholz AC, Stang JS et al. (2014) Impact of cooking and home food preparation interventions among adults: outcomes and implications for future programs. J Nutr Educ Behav 46, 259-276.

17. Crawford D, Ball K, Mishra G et al. (2007) Which food-related behaviours are associated with healthier intakes of fruits and vegetables among women? Public Health Nutr 10, 256-265.

18. Ducrot P, Méjean C, Aroumougame V et al. (2017) Meal planning is associated with food variety, diet quality and body weight status in a large sample of French adults. Int $J$ Behav Nutr Phys Act 14, 12.
19. Pew Research Center (2018) Mobile Fact Sheet. Washington, DC: Pew Research Center.

20. Flaherty S-J, McCarthy M, Collins A et al. (2018) Can existing mobile apps support healthier food purchasing behaviour? Content analysis of nutrition content, behaviour change theory and user quality integration. Public Health Nutr 21, 288-298.

21. Clarke P, Evans SH \& Neffa-Creech D (2019) Mobile app increases vegetable-based preparations by low-income household cooks: a randomized controlled trial. Public Health Nutr 22, 714-725.

22. Mauch CE, Wycherley TP, Laws RA et al. (2018) Mobile apps to support healthy family food provision: systematic assessment of popular, commercially available apps. JMIR Mhealth Uhealth 6, e11867.

23. Hingle M \& Patrick H (2016) There are thousands of apps for that: navigating mobile technology for nutrition education and behavior. J Nutr Educ Behav 48, 213-218.e1.

24. Creswell J \& Plano-Clark V (2011) Designing and Conducting Mixed Methods Research. Thousand Oaks, CA: SAGE Publications, Inc.

25. Glanz K, Rimer BK \& Viswanath K (2008) Health Behavior and Health Education: Theory, Research, and Practice, 4th ed. San Francisco, CA: Jossey-Bass.

26. Byrd-Bredbenner C (2005) Food preparation knowledge and confidence of young adults. J Nutr Recipe Menu Dev 3, 37-50.

27. Quam J (2016) Food Skills Research Project. Washington, DC: Share Our Strength.

28. Ajzen I (1985) From intentions to actions: a theory of planned behavior. In Action Control, pp. 11-39 [PDJ Kuhl and DJ Beckmann, editors]. Berlin/Heidelberg: Springer.

29. Corbin J \& Strauss A (2007) Basics of Qualitative Research: Techniques and Procedures for Developing Grounded Theory, 3rd ed. Los Angeles, CA: SAGE Publications, Inc.

30. Virudachalam S, Long JA, Harhay MO et al. (2014) Prevalence and patterns of cooking dinner at home in the USA: National Health and Nutrition Examination Survey (NHANES) 2007-2008. Public Health Nutr 17, 1022-1030.

31. Wolfson JA \& Bleich SN (2015) Is cooking at home associated with better diet quality or weight-loss intention? Public Health Nutr 18, 1397-1406.

32. Hartmann C, Dohle S \& Siegrist M (2013) Importance of cooking skills for balanced food choices. Appetite 65, 125-131.

33. Lavelle F, McGowan L, Spence M et al. (2016) Barriers and facilitators to cooking from 'scratch' using basic or raw ingredients: a qualitative interview study. Appetite 107, 383-391.

34. Wolfson JA, Bleich SN, Smith KC et al. (2016) What does cooking mean to you? Perceptions of cooking and factors related to cooking behavior. Appetite 97, 146-154.

35. Fiese BH, Gundersen C, Koester B et al. (2016) Family chaos and lack of mealtime planning is associated with food insecurity in low income households. Econ Hum Biol 21, $147-155$.

36. Dubowitz T, Cohen DA, Huang CY et al. (2015) Using a grocery list is associated with a healthier diet and lower BMI among very high-risk adults. J Nutr Educ Behav 47, 259-264.

37. Green LW, Ottoson JM, García C et al. (2009) Diffusion theory and knowledge dissemination, utilization, and integration in public health. Annu Rev Public Health 30, 151-174. 